\title{
8
}
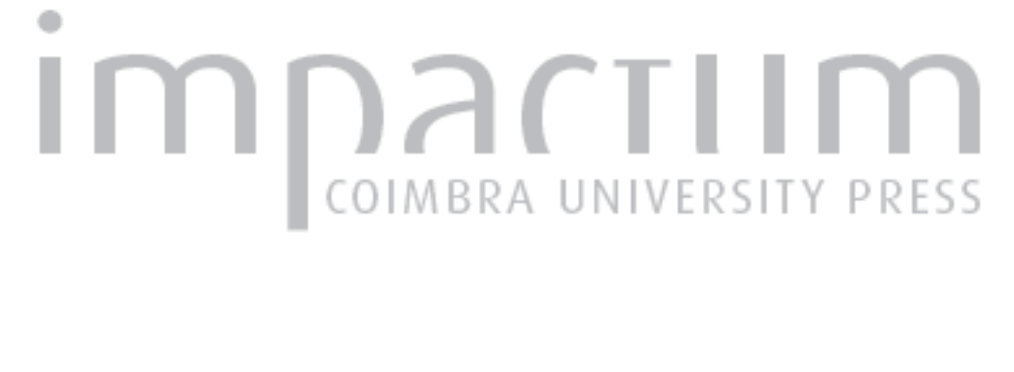

\section{[Recensão a] Patrizia Sabbatini Tumolesi, Epigrafia anfiteatrale delVOccidente Romano: I. Roma}
Autor(es):
D’Encarnação, José

Publicado por: Imprensa da Universidade de Coimbra

URL persistente:

URI:http://hdl.handle.net/10316.2/45592

DOI:

DOI:https://dx.doi.org/10.14195/1647-8657_27_9

Accessed : $\quad$ 26-Apr-2023 06:36:54

A navegação consulta e descarregamento dos títulos inseridos nas Bibliotecas Digitais UC Digitalis, UC Pombalina e UC Impactum, pressupõem a aceitação plena e sem reservas dos Termos e Condições de Uso destas Bibliotecas Digitais, disponíveis em https://digitalis.uc.pt/pt-pt/termos.

Conforme exposto nos referidos Termos e Condições de Uso, o descarregamento de títulos de acesso restrito requer uma licença válida de autorização devendo o utilizador aceder ao(s) documento(s) a partir de um endereço de IP da instituição detentora da supramencionada licença.

Ao utilizador é apenas permitido o descarregamento para uso pessoal, pelo que o emprego do(s) título(s) descarregado(s) para outro fim, designadamente comercial, carece de autorização do respetivo autor ou editor da obra.

Na medida em que todas as obras da UC Digitalis se encontram protegidas pelo Código do Direito de Autor e Direitos Conexos e demais legislação aplicável, toda a cópia, parcial ou total, deste documento, nos casos em que é legalmente admitida, deverá conter ou fazer-se acompanhar por este aviso.

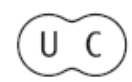


FACULDADE DE LETRAS

INSTITUTO DE ARQUEOLOGIA

\title{
CONIMBRIGA
}

\author{
VOLUME XXVII
}

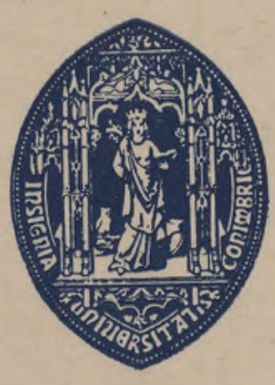

UNIVERSIDADE DE COIMBRA

1988 

tição.

N. ${ }^{\circ} 140=95$ ( = RAP 644). Como já observámos, há aqui ama repe-

N. 142 ( = RAP Z3). Com base no testemunho de Mário Cardoso, julgamos que esta ara é de Campo da Roda e não de Vila Verde. Nela não se vislumbra nada de seguro.

P. S. - Já com esta recensão elaborada, tivemos conhecimento de que ao volume em causa foi acrescentado um outro, com 191 páginas, constituído por um «Apêndice Fotográfico», onde se reedita o conjunto das fotografias, um pouco melhoradas, e se acrescentam novas descobertas numa «Recentissima Adenda Epigráfica».

\section{José Manuel Garcia}

Patrizia Sabbatini Tumolesi, Epigrafia anfiteatrale delVOccidente Romano: I. Roma. N. ${ }^{\circ} 2$ da colecção «VETERA - Ricerche di Storia, Epigrafìa e Antichità» dirigida por Silvio Panciera. Edizioni Quasar, Roma, 1988, 188 páginas, que integram 29 de estampas. ISBN 88-85020-95-X.

Pretende-se, corn esta série, fazer «uma recolha e um reexame sistemático dos numerossíssimos documentos de tema gladiatòrio actualmente dispersos», porque só assim «se poderá trazer alguma luz a tantos aspectos duvidosos e pouco explorados deste vasto campo da antiguidade e da história romana». Louis Robert concretizara, para o Oriente, tal desiderato; cabe agora reunir o material do Ocidente.

Como muito bem observa a Autora, ao tempo dos Romanos (como ainda hoje), o mundo do espectáculo reveste-se da maior importância, se se atender ao universo de interesses que o rodeiam : «o numerarius promove a sua ascensão social, a cidade o seu equilíbrio, o gladiador e o venator aspiravam à fama e o próprio imperador, acima dos demais, promovia mediante este tipo de espectáculos uma comunicação específica com as massas populares» (p. 7).

Por outro lado, a Epigrafia desempenha também aqui um papel imprescindível como fonte histórica: «Só através da análise das inscrições se torna, porventura, possível chegar a uma reconstituição verosímil do status jurídico-profissional do gladiador, doutra forma não claramente definível; é predominantemente da documentação epigráfica que emerge a maior ou menor difusão destes espectáculos, nos vários locais e vos vários tempos, e a sua repercussão nos diversos estratos sociais» (ibidem). A recolha está, pois, plenamente justificada e devidamente realçada a importância da iniciativa levada a cabo pela escola de Roma, tanto mais que desde já se anuncia no prelo o volume II, de Gian Luca Gregori, sobre as Regiones Italiae VI-XI.

A obra de Patrizia Sabbatini Tumolesi, acabada de imprimir em Maio de 1988, está dividida em duas partes. Apresenta-se, na primeira, o catálogo, 
estando os textos agrupados por temas: a administração dos munera (secção I), munera e venationes (secção II), gladiadores e escolas gladiatorias (secção III). A segunda é uma síntese dos dados obtidos, exposta em dezasseis tabelas, de fácil visualização. Seguem-se-lhe oportunas considerações gerais, onde são abordadas as questões fundamentais que os monumentos despertam: a administração dos espectáculos; munera e venationes; os jogos e o treino; os gladiadores por conta pròpria [liberi) ; observações acerca da profissão; as especialidades; a onomástica como índice do status jurídico do gladiador; e aspectos da vida privada.

A finalizar, índices analíticos muito completos que abarcam os seguintes aspectos: autores modernos, fontes literárias, fontes epigráficas. Nos índices epigráficos propriamente ditos são incluídas as seguintes rubricas: nomina (onde se insere o nome co mpleto da personagem citada) ; cognomina (de novo, o nome completo quand o é caso disso, o que muito facilita a investigação) ; tribo ; teónimos ; sacra; im peradores e membros da casa imperial (com a indicação expressa de como vêm designados); organização político-administrativa (datas, cargos); organização militar; colégios, artes e ofícios; notabilia varia (com a palavra no singular e, depois, o contexto frásico em que se insere, o que é de extrema utilidade); particularidades linguísticas.

Por último, fotografias de todos os monumentos actualmente conservados, recorrendo-se, num caso (n. $\left.{ }^{\circ} 92\right)$, à inclusão da gravura que representa um monumento perdido.

No catálogo, apresentam-se os dados essenciais que identificam o monumento epigráfico: brevíssima descrição, indicação da proveniência e do local de conservação, identificação do negativo fotográfico e da reprodução fotográfica no volume; cita-se a bibliografia (corpora e estudos). A inscrição é apresentada em minúsculas e a disposição das linhas obedece ao original do monumento. Após a referência às variantes de leitura, não se faz a tradução da epígrafe, preferindo-se uma síntese explicitada do seu conteúdo. O comentário, breve, realça a importância das informações contidas no documento - cingindo-se, porém, ao âmbito do tema - e termina pela proposta, justificada, de datação.

Após termos visto a panorâmica geral da obra, realçante já por si do seu elevado interesse histórico e documental, comentemos uma que outra passagem que particularmente nos despertou a atenção.

Destaque-se, por exemplo, a informação contida no texto $\mathrm{n} .^{\circ} 8$, dedicado a um procurator Laurento ad elephantos, que nos elucida sobre a existência, junto da via Laurentina, de urn vivarium de elefantes, animais que eram "prerrogativa e símbolo do imperador, que os empregava nos seus munera e nas pompae». À frente desse depòsito estava, portanto, um procurator, liberto imperial.

No n. ${ }^{\circ} 13$, um texto funerário repleto de ternura e de intimidade familiar, as personagens (pai e filho) identificam-se apenas pelo antropònimo Marcus. Opina a autora que, por se tratar de um texto datável, verosimilmente, dos 
finais do séc. ui da nossa era, Marcus se deve entender «de preferência como cognomen» e não como praenomen. Não seria assim tão peremptório. É precisamente nos finais do séc. $m$ que se dá um retorno à simplicidade de tratamento inicial, quiçá por influência do Cristianismo (que seria, inclusive, tentado a detectar também na expressão laudatoria dulcis anima aí utilizada pelo filho). Por outro lado, o assinalado carácter íntimo do epitáfio poderá ir também nesse sentido de, no ambiente familiar, as pessoas se tratarem pelo seu primeiro nome. A epigrafia é, de resto, um bom testemunho do «diálogo» que persiste para além da morte.

No n. ${ }^{\circ} 17$, discute-se a possibilidade de, na 1.7 , estarem mencionados um, dois ou três dedicantes. A autora optou pela última hipótese, que se afigura, de facto, a mais lógica.

$\mathrm{O}$ n. ${ }^{\circ} 23$ é homenagem a T. Furius Yictorinus, que foi procurador da Hispânia Citerior. Interessa-nos especialmente porque Hübner considerou esta inscrição falsa (CIL II 396*); na esteira de Ch. Hülsen e de G. Pflaum, a autora reabilita-a.

O n. 26 (CIL VI 1645, ILS 2773) refere-se a um cavaleiro que, em meados do séc. $\mathrm{m}$, foi procurador da Lusitânia e $d u x$ das legiões da Dàcia. Não se conhece a sua identidade, pelo que só anonimamente o poderemos incluir nos fastos da província. Contudo, não será despropositado sublinhar a circunstância, que de novo se observa, de um membro da ordem equestre ter desempenhado funções na Lusitânia e na Dàcia. Recorde-se que Caius Iulius Celsus, memorado numa epígrafe de Odrinhas, após ter sido procurador da Lusitânia, desempenhou também funções equestres na Dàcia Superior, nos finais do séc. n (cf. Scarlat Lambrino, Les inscriptions de São Miguel d'Odrinhas, «Bulletin des Études Portugaises...», nova série, XYI, 1952, p. 134-176, n. ${ }^{\circ} 24$, p. 142-150).

Na leitura do . $^{\circ} 27$, não foi assinalada, por lapso, a omissão do $\mathrm{N}$ na palavra coniux.

Bem observado, no comentário ao n. ${ }^{\circ} 28$ (CIL VI 10 164), o facto de, por a filha ter gentilicio diferente do do pai, ser muito provavelmente o fruto de uma união ilegítima. A presença do adjectivo sanctissima aplicado à esposa - que não é, no entanto, a mãe da jovem defunta - vem realçar o clima de ternura em que estavam envolvidas as relações familiares entre os libertos, como muito bem frisou G. Fabre em relação aos finais da República \{Libertus, Roma, 1981, p. 192-195).

Bem argumentada a manutenção da leitura usu na 1.5 do texto n. $^{\circ} 34$, em vez de se considerarem hipóteses de erro por parte do lapicida, quando a palavra está bem clara e encontra justificação.

O epitáfio de Menander (n. ${ }^{\circ}$ 40, CIL VI 6227) documenta eloquentemente a sobriedade da epigrafia romana: destinado a figurar no monumento dos Statilii, não precisava de identificar o defunto com praenomen e nomen, perfeitamente subentendíveis. Daqui ressalta, por outro lado, a importância de se conhecer o melhor possível o contexto arqueológico original das epígrafes e, ainda, o cuidado a ter, por vezes, na apresentação de hipóteses explicativas da onomástica, nomeadamente se se não tem em conta esse contexto. 
Merece atenção, no comentário ao texto 45, o significado atribuído ao termo paganus: qualifica quem é estranho ao mundo dos gladiadores. Esse texto, datado do ano 177, reveste-se, aliás, de particular interesse por enumerar os membros do colégio chamado «de Silvano Aureliano», por ter sido posto sob a protecção do deus Silvano, no tempo do imperador Còmodo. Eram 32, de várias categorias, divididos em quatro decúrias: na primeira estavam integrados os veterani; na segunda, encabeçada por um veteranus, estavam os tirones, gladiadores prontos para o primeiro combate, assim como um fabricante de mangas couraçadas (manicarius) e um massagista (unctor) ; a composição da terceira decúria é menos uniforme (tirones, um noviço e um paganus) ; na quarta decúria, de apenas dois elementos, surge um lutador de spatha (espada) e um paegniarius, curiosa figura de bufão que animaria o intervalo dos combates.

Os epitáfios dos gladiadores são deveras eloquentes na sua simplicidade. Tal como um toureiro da actualidade que se vangloria de, no seu currículo, contar tantas «orelhas» e «rabos» cortados na lide, assim por exemplo os familiares do essedarius Máximo não se esquecem de lhe assinalar sobre a tumba que, dos 40 combates em que participou, em 36 foi particularmente feliz, tendo sido galardoado com palma ou com corona (n. ${ }^{\circ} 68$ ). Entra-se, assim, pela Epigrafia, no âmago do que, de facto, o mundo do espectáculo tem de complexo e, ao mesmo tempo, de profundamente humano.

$\dot{E}$, de resto, nesse sentido, que se encaminhou a autora na segunda parte do seu livro. O pormenor significativo que mostra como o aliciante do munus reside, de modo particular, no heroísmo com que se enfrenta a morte, consubstanciado na cena ideal em que o vencido entrega ao adversário o gládio que o irá matar... (p. 131). A impossibilidade de, no âmbito da vida privada, saber qual a média de vida, o número de combates por ano, a existência familiar (p. 139). Os epitáfios documentam, no entanto, a existência de sodalicios fúnebres: referem-se os sodales (n.os 83 e 84 ), a familia gladiatoria (n. os 45-47), os compatriotae (n. ${ }^{\circ} 81$ ), os amici (n. os 90 e 105). E é bem possível que tais confrarias pudessem ter mesmo um recinto sepulcral próprio (p. 140).

Quanto aos índices, talvez fosse preferível que, em vez de um simples índice de «autores modernos», se tivesse inserido também uma bibliografia à maneira tradicional. Assim, por exemplo, embora a obra se refira exclusivamente a Roma, poderia ter interesse para o leitor saber que a citação de A. García y Bellido feita na pág. 61 diz respeito ao artigo Lapidas funerarias de gladiadores de Hispania (AEA 331960 123-144). De P. Piernavieja cita-se (p. 61) um texto de 1970, que é - sabemo-lo após consulta de ficheiros - Esteia funerária del sagitario Tito Flavio Expedito (AEA 431970 203-212); mas, se não se tiver um ficheiro especializado à mão, fica-se sem saber se merecerá a pena consultar o texto, também citado (p. 65), inserto na revista «Ampúrias», quando do mesmo autor há o volume, não referido, Corpus de inscripciones deportivas de la España romana (Madrid, 1977) ou o artigo, também não citado, Repercusión social de los deportistas en la España romana («Citius Altius Fortius» 131971 141-147) sobre os jogos como despesa pública e como fonte de sucesso e popularidade.

Conimbriga, 27 (1988), 203-220 
Aqui e além, a autora assume-se como falante apenas para o público restrito dos epigrafistas encantados. A expressão itu ambitu do n. ${ }^{\circ} 10$, que não é assim tão corrente como isso nos corpora epigráficos, poderia ter merecido da sua parte um pequeno comentário lateral, ainda que apenas para citar bibliografia ou um paralelo. E se o índice das fontes literárias poderá ser acessível porque a forma de citar os clássicos é quase universal, o mesmo se não poderá dizer das fontes epigráficas, onde há siglas como ICUR, IGRRP, IGUR, OGIS e outras, não explicitadas em sítio nenhum do trabalho. Inclusive as citações das publicações periódicas parecem não obedecer aos critérios do «Année Philologique»: os «Rendiconti dell'Academia dei Lincei», habitualmente citados pelas siglas RAL, são referidos como Rend. Acc. Line. (p. 148); os «Rendiconti della Pontificia Accademia di Archeologia» (RPAA) vêm indicados Rend. Pont. Acc. Arch, (ibidem).

Uma palavra sobre o álbum fotográfico. As fotografias são, em geral, de muito boa qualidade. Importaría, aqui e além, que se tivesse isolado o monumento epigráfico por meio dum fundo neutro que o valorizasse e facilitasse a sua leitura formal (v. g.: tav. VIH, 1; XVII, 3; XXI, 2), inclusive por obediência a preceitos de apresentação estética (tav. XI, 2; XVIII, 1; $\mathrm{XX}, 5$ - que se refere ao n. $^{\circ} 87$ e não ao 95 , que é o da foto 3 ).

E se é de louvar a oportunidade e o elevado interesse científico da iniciativa, há que fazer também uma menção aos editores, porque Edizioni Quasar, de Severino Tognon, estão a prestar um excelente contributo aos epigrafistas: lançaram ombros à publicação de «Vetera», mas é da mesma casa editora um outro empreendimento igualmente válido e espinhoso, a publicação da nova série dos Supplementa Italica, de que já recebemos o n. ${ }^{\circ} 3$ (1987). São obras que, merecedoras muito embora do maior encómio do ponto de vista científico, não serão, certamente, à partida, um êxito livreiro, dado o seu carácter muito específico. Que também o possam vir a ter - são os meus votos, porque, de facto, bem o merecem. 